\title{
GUIAS DE BIBLIOTECAS COMO FONTES DE INFORMAÇÃO: METODOLOGIA DE ELABORAÇÃO DO GUIA DA $1^{\text {a }}$ REGIÃO
}

\section{GUÍAS DE LAS BIBLIOTECAS COMO FUENTES DE INFORMACIÓN: METODOLOGÍA DE ELABORACIÓN DE LO GUÍA DE LA 1ª REGIÓN}

\author{
Tatiara Paranhos Guimarães - tatiaraguimaraes@yahoo.com.br \\ Mestre em Ciência da Informação pela Universidade de Brasília (UNB). \\ Coordenadora do Serviço de Referência do Centro de Informação e Pesquisa da \\ Embaixada dos Estados Unidos .Coordenadora da Comissão de Divulgação do Conselho \\ Regional de Biblioteconomia - 1ª Região, Gestão 2006/2008 \\ Cristine Coutinho Marcial - cristine.marcial@planejamento.com.br \\ Pós-graduada em Gestão de Tecnologia da Informação (GTI) pela ENAP/TECSOFT \\ Bacharel em Biblioteconomia pela Fundação Universidade de Brasília (UnB) \\ Chefe da Biblioteca do Ministério do Planejamento, Orçamento e Gestão e Vice- \\ Presidente do Conselho Regional de Biblioteconomia - $1^{\text {a }}$ Região, Gestão 2006/2008.
}

\section{Resumo}

Este trabalho ressalta o papel do Conselho Regional de Biblioteconomia na elaboração e manutenção de cadastros de bibliotecas e unidades de informação, a importância dos cadastros de bibliotecas e unidades de informação para a divulgação destas entidades, bem como fontes bibliográficas para informações de interesse do usuário. Apresenta, também, as iniciativas de profissionais e instituições na publicação de Guias de bibliotecas no Brasil. Por fim, descreve a metodologia utilizada para o cadastramento das Bibliotecas que resultou na publicação do "Guia de Bibliotecas da $1^{\text {a }}$ Região" em formato impresso e eletrônico.

\section{Palavras-chave}

Fontes de informação. Guia de bibliotecas. Diretório de bibliotecas. 


\section{INTRODUÇÃO}

O uso regular e efetivo de fontes de informação apropriadas constitui-se em requisito importante para atividades de pesquisa e desenvolvimento e em atividades ligadas à ciência e tecnologia (CUNHA, 2001).

De acordo com Grogan (1970 apud CUNHA, 2001), as fontes de informação podem ser divididas em três categorias: documentos primários, secundários $\mathrm{e}$ terciários. Estes últimos têm como função principal guiar o leitor na pesquisa de fontes primárias e secundárias, servindo como sinalizadores de localização de documentos primários. Diretórios ou cadastros, classificados como documentos terciários, compreendem conjuntos com informações e dados sobre pessoas e organizações, tais como endereço, produtos e serviços ofertados e outras informações similares (CUNHA, 2001).

No contexto das bibliotecas universitárias, fontes terciárias, como guias e cadastros de bibliotecas, representam instrumento essencial para identificar as unidades de informação apropriadas para apoiar as pesquisas desenvolvidas por professores, estudantes universitários e pesquisadores em geral. $\mathrm{O}$ Guia de Bibliotecas da $1^{\text {a }}$ Região (CONSELHO REGIONAL DE BIBLIOTECONOMIA CRB - 1. REGIÃO, 2008), desenvolvido com o objetivo de divulgar os serviços e produtos oferecidos por essas unidades, também direciona o usuário para a fonte ou unidade de informação mais apropriada para a consulta por material bibliográfico.

Este artigo tem $\mathrm{O}$ objetivo de descrever o processo e metodologia utilizados para a elaboração e publicação do referido Guia, servindo como suporte para futuras iniciativas deste gênero. Para tanto, este trabalho ressalta o papel de Conselhos de Classe na elaboração e manutenção de Guias de Bibliotecas, apresenta as principais recomendações da norma brasileira que trata sobre a preparação de guias de bibliotecas, comenta e analisa $o$ resultado de levantamento realizado sobre os principais Guias de bibliotecas publicados no Brasil. Por fim, descreve as principais etapas percorridas para a elaboração do Guia de Bibliotecas da $1^{\text {a }}$ Região, publicado em 2008, bem como as especificidades do sistema de cadastro online utilizado para o cadastramento destas bibliotecas.

\section{PAPEL DOS CONSELHOS DE CLASSE: CADASTRO DOS CENTROS DE INFORMAÇÃO, DOCUMENTAÇÃO E BIBLIOTECAS}

O Conselho Regional de Biblioteconomia $1{ }^{\text {a }}$ Região (CRB-1) possui sede no Distrito Federal e jurisdição nos Estados de Goiás, Mato Grosso e Mato Grosso do Sul. Este órgão possui 
personalidade jurídica de direito público, autonomia financeira, administrativa e patrimonial e é unidade regional do Conselho Federal de Biblioteconomia (CFB).

O Regimento Interno desse Conselho foi aprovado pelo CFB por meio da Resolução $n^{\circ}$ 226/79 de 10 de fevereiro de 1979 e institui o regime jurídico, determina a natureza, as finalidades, as atribuições, a constituição, a estrutura, a competência e as atividades desta entidade, bem como as prerrogativas e as responsabilidades de seus membros.

Segundo $\circ$ Art. $7^{\circ}$ do Regimento Interno, o CRB-1 possui as seguintes finalidades:

a) zelar pelo bom conceito da profissão de bibliotecário;

b) orientar, aperfeiçoar, disciplinar e fiscalizar o exercício da profissão de bibliotecário com a promoção e utilização dos meios de maior eficácia presumida;

c) defender o livre exercício da profissão de bibliotecário;

d) julgar dentro de sua competência as infrações à Lei e a Ética profissional;

e) funcionar como órgão consultivo do Governo na região de sua jurisdição no que se refere ao exercício e aos interesses profissionais do bibliotecário;

f) contribuir para o aprimoramento da Biblioteconomia e de seus profissionais (CRB - 1 . REGIÃO, 2002).

Dentre as principais competências deste Conselho, o Art. 12, também do Regimento Interno, cita a organização e manutenção atualizada dos cadastros: a) dos profissionais registrados em seus quadros;

b) dos profissionais de atividades auxiliares da biblioteconomia;

c) de instituição de ensino da biblioteconomia em todos os seus níveis;

d) de instituições de formação de profissionais de atividades auxiliares da biblioteconomia e;

e) das bibliotecas, bancos de dados bibliográficos, centros e serviços de documentação, informação e/ou informática, centros de multimeios e demais entidades e/ou instituições que tenham como objetivo o armazenamento e/ou disseminação da informação em qualquer área de atividade intelectual (CRB - 1. REGIÃO, 2002).

Baseando-se nessa última competência, a Gestão do CRB-1 20062008 compôs comissão para atualização e organização do Guia de Bibliotecas da $1^{\text {a }}$ Região, disponibilizando os cadastros das unidades de informação do Distrito Federal e dos Estados de Goiás, Mato Grosso e Mato Grosso do Sul em versão eletrônica e impressa.

\section{DIRETRIZES PARA A ELABORAÇÃO DE GUIAS DE BIBLIOTECAS NO BRASIL}

No Brasil, a ABNT (ASSOCIAÇÃO BRASILEIRA DE NORMAS TÉCNICAS, 1992) editou norma para preparação de guia de bibliotecas e centros de documentação. Esta norma define guia como: "obra de referência, periódica ou não, que informa nome, endereço, 
tamanho da(s) coleção(ões), assunto(s) coberto(s), recursos humanos e outros dados relativos a bibliotecas, centros de informação e documentação".

As informações essenciais e opcionais que devem constar no guia são definidas nesse documento, a saber:

a) Essenciais: nome oficial do centro ou biblioteca, seguido de sigla; nome da instituição hierarquicamente superior; endereço completo, endereço telegráfico, número do telefone e código da área, números do fax; horário de atendimento; tipo de biblioteca; público a que serve; assuntos principais e correlatos do acervo; tipo de acesso às estantes: livre ou indireto; tipo de empréstimo; serviços fornecidos; sistema de cobrança para o fornecimento dos serviços; base de dados assinadas; meio e tipo de acesso a estas bases.

b) Opcionais: histórico do centro ou biblioteca, nome do chefe do centro ou biblioteca; quadro de funcionários; publicações; número total de volumes, de títulos de periódicos, de microformas, de mapas e outros documentos especiais; área da biblioteca ou centro; processos técnicos; sistema de automação (ABNT, 1992).
Outra questão tratada na norma da ABNT é o tipo de arranjo ou organização do Guia, podendo relacionar os centros ou bibliotecas em ordem alfabética, geográfica, de assunto ou por tipo de documento.

Para facilitar a busca pelas informações disponíveis no cadastro, o guia deve ser acompanhado de índices remissivos, com remissivas dos nomes alternativos, siglas, traduções, etc. das bibliotecas ou centros, observando-se a norma NBR 6034 (ABNT, 1989).

A estrutura e organização do Guia de Bibliotecas da $1^{\text {a }}$ Região, elaborado pelo Conselho Regional de Biblioteconomia $1^{\text {a }}$ Região (2008) foi baseado parcialmente nesta norma em outros diretórios de bibliotecas consultados.

\section{LEVANTAMENTO DOS GUIAS E DIRETÓRIOS PUBLICADOS NO BRASIL}

É interessante observar o elevado número de guias e diretórios de bibliotecas e unidades de informações já publicados no Brasil. Diversas associações de bibliotecários, conselhos de classe, universidades e instituições tomaram a iniciativa de coletar e de publicar dados sobre estas instituições, facilitando a busca por parte de usuários e profissionais pelas fontes de informação apropriadas para sua consulta. 
O levantamento das publicações comentadas a seguir foi realizado por intermédio de busca no catálogo online da Biblioteca do IBICT (Instituto Brasileiro de Informação em Ciência e Tecnologia), maior biblioteca especializada na área de Ciência da Informação no Brasil; busca no catálogo online da Biblioteca Central da Universidade de Brasília, a qual possui um riquíssimo acervo nesta área de especialidade; e pesquisa no Google. Apesar de o levantamento não ter sido exaustivo, retrata as inúmeras iniciativas realizadas por profissionais e instituições na publicação de fontes de informação sobre unidades de informação. A seguir, os guias, cadastros e diretórios recuperados na pesquisa bibliográfica realizada são citados e comentados.

O primeiro guia publicado pelo Conselho Regional de Biblioteconomia $1^{\text {a }}$ Região foi o Guia das Bibliotecas de Brasília, em 1975. No ano de 1981, publicou documento mais completo contendo informações sobre as bibliotecas de sua jurisdição, o qual incluía, além do Distrito Federal, Goiás, Mato Grosso e do Mato Grosso do Sul, o Estado do Acre e o antigo Território de Rondônia. Este mesmo Conselho lançou, em 1996, o Cadastro de Bibliotecas do Distrito Federal e em 2008 o Guia de Bibliotecas da $1^{a}$ Região, contendo dados sobre as unidades de informação do Distrito Federal, Goiás, Mato Grosso e Mato Grosso do Sul, disponível em versão impressa e online (CRB - 1. REGIÃO, 1975, 1981, 1996, 2008). Percebe-se que apesar de o CRB-1 ter publicado vários guias, os intervalos entre as publicações são grandes, gerando, com isso, dúvidas quanto à atualização das informações.

Outros documentos contendo dados sobre as bibliotecas do Distrito Federal e de Brasília foram encontrados. A Associação dos Bibliotecários do Distrito Federal $(1970,1985)$ publicou o Guia das Bibliotecas de Brasilia em 1970 e o Diretório de Bibliotecas e/ou Centros de documentação, em 1985.

Outros conselhos de classe também publicaram guias e cadastros das bibliotecas de suas jurisdições, tais como o Conselho Regional de Biblioteconomia $8^{a}$ Região (1988) que editou o cadastro das Bibliotecas do Estado de São Paulo; e o Conselho Regional de Biblioteconomia $7^{a}$ Região (1993) que publicou o Guia de bibliotecas, centros de documentação e informação do Estado do Rio de Janeiro. Nota-se que são poucas as iniciativas de Conselhos de Classe, apesar de a organização e manutenção de cadastros de bibliotecas ser citada como uma de suas competências principais.

Ainda relacionando os Guias e diretórios publicados em âmbito estadual e local, na Região Sul, Tavares (1973) publicou diretório das bibliotecas localizadas no Rio Grande do Sul entre os anos de 1971 e 1972. O Guia das 
Bibliotecas da grande Porto Alegre foi publicado por Negrine (1976) com o intuito de servir como fonte para a pesquisa bibliográfica educacional.

Na Região Nordeste, a Associação de Bibliotecários de Pernambuco (1971) publicou a $2^{\text {a }}$ edição do Guia das bibliotecas e bibliotecários do Recife; o Guia das bibliotecas de Teresina foi lançado por Santos $(1980,1983)$ em duas edições. Caldeira (1977) lançou o Guia das Bibliotecas do Estado de Minas Gerais. As iniciativas de profissionais são observadas nas publicações de guias estaduais e locais.

Com relação aos Guias das bibliotecas públicas, em 1960, o Departamento de Estatística do Estado de São Paulo publicou o cadastro, por município, das Bibliotecas Públicas e Semipúblicas do Estado. Este mesmo Guia foi atualizado e publicado novamente em 1961 (SÃO PAULO, 1960, 1961). Em 1988, a Secretaria de Estado da Cultura (SÃO PAULO, 1988) publicou o Guia das Bibliotecas Públicas Municipais do Estado de São Paulo.

No ano de 1979, o Instituto Estadual do Livro publicou o cadastro das Bibliotecas estaduais e municipais do Rio de Janeiro. E, em 1983, o Instituto Nacional do Livro lançou o Guia das bibliotecas públicas brasileiras conveniadas com o Instituto Nacional do Livro (INSTITUTO ESTADUAL DO LIVRO,
1979; INSTITUTO NACIONAL DO LIVRO, 1983). A Fundação Biblioteca Nacional (1994), por sua vez, publicou o Guia das bibliotecas públicas do Brasil entre os anos de 1994 e 1995. Apesar de existir um sistema de bibliotecas públicas no Brasil, coordenado pela Fundação Biblioteca Nacional, os cadastros dessa categoria de unidades de informação estão desatualizados.

Diversos guias publicados registraram dados de bibliotecas brasileiras em geral, tais como o Guia das bibliotecas brasileiras publicado pelo Instituto Nacional do Livro (1969), em sua $4^{a}$ edição; o Guia publicado pela Fundação Instituto Brasileiro de Geografia e Estatística (1979), o guia de bibliotecas, centros e serviços de documentação publicado pelo Instituto Brasileiro de Informação em Ciência e Tecnologia (IBICT, 1987) e o guia de bibliotecas e centros de documentação editado pelo Conselho Nacional de Desenvolvimento Científico e Tecnológico (CNPQ, 1982). Baseando-se nas datas destas publicações, julga-se necessário a publicação de guia de bibliotecas brasileiras atualizado.

No âmbito das bibliotecas especializadas são numerosos os documentos recuperados, dentre estes: Bibliotecas especializadas brasileiras, em sua $2^{\mathrm{a}}$ edição, publicada pelo antigo Instituto Brasileiro de Bibliografia e Documentação (1969); Bibliotecas em 
tecnologia do Estado de São Paulo, publicado pela Associação Paulista de Bibliotecários e Grupo de Trabalho em Tecnologia (1970); esta mesma Associação publicou o Guia de Bibliotecas de Ciências Sociais e Humanas do Estado de São Paulo (1973); em 1977, Carvalho, Santos e Figueiredo (1977) publicaram o Guia das bibliotecas e serviços de documentação da área tecnológica do Rio de Janeiro; Carvalho, Raposo e Figueiredo (1979) também publicaram o Guia de bibliotecas e serviços de documentação da área tecnológica dos estados do Paraná e do Rio Grande do Sul; o Serviço Nacional de Aprendizagem Industrial do Rio de Janeiro (1986) publicou o Diretório de bibliotecas e centros de documentação SENAI/EMPRESAS; na área jurídica, a Comissão Brasileira de Informação e Documentação Jurídica (1994) publicou o Guia de bibliotecas jurídicas, em sua $2^{\text {a }}$ edição; neste mesmo ano, a Associação Paulista de Bibliotecários (1994) lançou o Guia de bibliotecas jurídicas do Estado de São Paulo, em sua $2^{\mathrm{a}}$ edição; na área de educação, Hirschberg et al. (1990) publicaram o Cadastro de unidades de documentação e bibliotecas brasileiras de educação.

No âmbito das bibliotecas universitárias, percebe-se iniciativas de universidades sobre seus sistemas de bibliotecas, bem como guias de bibliotecas de instituições de ensino superior em geral.
O guia mais antigo recuperado foi o Guia das bibliotecas da Universidade de São Paulo, lançado em 1973, e reeditado em 1978 e no ano de 1988 (USP, 1973, 1978, 1988). Em 1979, a Biblioteca Central da Universidade Federal do Piauí (1979) lançou o Guia das bibliotecas universitárias brasileiras. O Guia de bibliotecas e unidades de informação UFRJ/SIBI foi publicado em 1988 e em 1991 pela Universidade Federal do Rio de Janeiro (UFRJ, 1988, 1991). Em nível nacional, a Capes publicou o Guia de bibliotecas universitárias brasileiras (BRASIL, 1979), a Universidade Federal do Rio de Janeiro publicou o Guia de bibliotecas de instituições brasileiras de ensino superior (UFRJ, 1994), Mogi (1996) lançou o Guia de bibliotecas de universidades federais e a Comissão Brasileira de Bibliotecas Universitárias (1998) vem publicando periodicamente Guia de bibliotecas de instituições brasileiras de ensino superior, que atualmente está disponível por meio da base de dados BIBES (Bibliotecas de Instituições Brasileiras de Ensino Superior) com acesso online.

Com o advento da Internet, percebese que diversos Guias estão sendo publicados online, facilitando a consulta e atualização dos dados, tais como o Guia de Bibliotecas do Sistema Indústria (CONFEDERAÇÃO NACIONAL DA INDÚSTRIA, 2005), Guia de bibliotecas e Postos de Serviços de Informação: 
SiBI/UFRJ (UFRJ, 2005); Guia de

Bibliotecas Públicas do Estado do Rio de Janeiro (RIO DE JANEIRO, 2002); Guia de Bibliotecas Públicas Municipais do Paraná (BIBLIOTECA PUBLICA DO PARANÁ, 2004) e o Guia de Bibliotecas da $1^{\text {a }}$ Região (CRB - 1. REGIÃO, 2008).

A metodologia e processos utilizados para a elaboração deste último são enumerados nas próximas seções.

\section{O GUIA DE BIBLIOTECAS DA $1^{\text {a }}$ REGIÃO}

O Guia de Bibliotecas da $1^{a}$ Região: Distrito Federal, Goiás, Mato Grosso e Mato Grosso do Sul disponibiliza informações para contato com bibliotecas, centros de informação e documentação localizados na região de jurisdição do CRB-1. O seu objetivo principal é o de divulgar informações sobre as unidades de informação tais como endereços, telefones, fax, e-mails, sites, tipos de documentos disponibilizados por essas bibliotecas, temas tratados nos acervos, serviços/produtos oferecidos e sistemas de classificação e de automação utilizados (CRB - 1. REGIÃO, 2008), apoiando bibliotecários, estudantes, profissionais atuantes e pessoas interessadas em localizar endereços e informações sobre estas instituições, facilitando a busca e recuperação de informações e documentos de seu interesse.
O Guia está organizado por Unidade da Federação (Distrito Federal, Goiás, Mato Grosso e Mato Grosso do Sul) e em segundo nível por tipo de biblioteca (escolar, universitária, especializada e pública). Nessa estrutura, as instituições mantenedoras estão listadas com as informações sobre suas bibliotecas, em ordem alfabética. Este ordenamento e as informações disponibilizadas levaram em consideração as recomendações da norma da Associação Brasileira de Normas Técnicas (1992).

A equipe responsável pelo trabalho, composta por duas conselheiras e pela bibliotecária fiscal do CRB-1, realizou um acurado levantamento de aproximadamente 500 unidades de informação por meio de sistema automatizado de cadastro de bibliotecas, disponível no site deste Conselho (www.crb1.org.br), abrangendo o ano de 2007. Contou-se também com a colaboração dos Delegados que compõem a jurisdição do CRB-1 para a realização deste trabalho. A metodologia utilizada para a elaboração deste Guia é descrita a seguir.

\section{METODOLOGIA DE ELABORAÇÃO DO GUIA DA $1^{\text {a }}$ REGIÃO}

Os dados disponíveis no Guia foram cadastrados por profissionais das próprias unidades de informação, por meio de 
formulário eletrônico disponível no site do às consultas e nas inserções de dados. CRB-1. A maioria das bibliotecas Devido à base ter sido construída com uma cadastradas localiza-se no Distrito Federal, arquitetura simples de tabelas, torna-se com aproximadamente 310 unidades, possível o desenvolvimento eficaz dos representando $62 \%$ do total. Constam no mais variados tipos de consultas, sistema aproximadamente 80 unidades do relacionando e filtrando os campos Estado de Goiás, 60 do Mato Grosso do cadastrados ou criando consultas prontas Sul e 45 de Mato Grosso. Ainda se para que retornem resultados para tratando do total de unidades cadastradas, pesquisas pontuais, sem utilização de aproximadamente 200 são especializadas, 160 universitárias, 100 escolares e 30 filtros, a exemplo de pesquisa onde são recuperadas as bibliotecas que tenham públicas. Estes números retratam a grande representatividade de bibliotecas de órgãos documentos relacionados com a área de saúde em seu acervo.

do governo, empresas e organizações que possuem acervo especializado, principalmente na cidade de Brasília, Distrito Federal.

\subsection{O FORMULÁRIO ELETRÔNICO}

A estrutura do formulário eletrônico (http://www.crb1.org.br/cadastros/

\subsection{ESPECIFICAÇÕES TECNOLÓGICAS DO CADASTRO ONLINE}

$O$ cadastro on line de bibliotecas do CRB-1 foi desenvolvido utilizando tecnologia $100 \%$ open source, baseada na linguagem de programação PHP e banco de dados MySql. Sua manutenção pode ser realizada por qualquer profissional com conhecimentos nessas tecnologias e ter uma performance adequada na respostas

bibliotecas/bibliotecas cadastrar biblio.php ) foi definida com base nas orientações disponíveis na norma da Associação Brasileira de Normas Técnicas (1992), disponibilizando os campos e subcampos com os níveis especificados no quadro 1 a seguir: 


\begin{tabular}{|c|c|}
\hline CAMPOS & SUBCAMPOS \\
\hline Informações institucionais & $\begin{array}{l}\text { nome da biblioteca ou centro de informação, } \\
\text { sigla, entidade mantenedora, horário de } \\
\text { funcionamento. }\end{array}$ \\
\hline Dados do responsável pela biblioteca & nome e cargo. \\
\hline Informações para contato com a biblioteca & endereço completo, telefones, fax, e-mail e site. \\
\hline Recursos humanos em números & $\begin{array}{l}\text { número de bibliotecários, de auxiliares, de } \\
\text { estagiários e outros. }\end{array}$ \\
\hline Tipo de biblioteca & $\begin{array}{l}\text { Escolar (pública ou privada) } \\
\begin{aligned} & \text { Especializada } \\
& \text { - governamental } \\
& \text { - federal } \text { - Poder Executivo } \\
& \text { - Poder Legislativo } \\
& \text { - Poder Judiciário } \\
& \text { - estadual } \text { - Poder Executivo } \\
& \text { - Poder Legislativo } \\
& \text { - Poder Judiciário } \\
& \text { - municipal } \\
& \text { - Poder Executivo } \\
& \text { - Poder Legislativo } \\
& \text { - iniciativa privada } \\
& \text { - organização não-governamental Judiciário } \\
& \text { - organismo internacional } \\
& \text { - outro }\end{aligned} \\
\text { Pública (estadual ou municipal) } \\
\text { Universitária (pública ou privada) } \\
\text { Outro }\end{array}$ \\
\hline Tipo de documentos disponibilizados & $\begin{array}{l}\text { livros, jornais, teses, fotos, periódicos, diários } \\
\text { oficiais, monografias, normas, mapas, multimídia, } \\
\text { relatórios. }\end{array}$ \\
\hline Temática do acervo & $\begin{array}{l}\text { Geral } \\
\begin{array}{l}\text { Especializada }{ }^{1} \\
\text { - Ciências Exatas e da Terra } \\
\text { - Ciências Biológicas } \\
\text { - Engenharias } \\
\text { - Ciências da Saúde } \\
\text { - Ciências Agrárias } \\
\text { - Ciências Sociais Aplicadas } \\
\text { - Ciências Humanas } \\
\text { - Lingüística, Letras e Artes }\end{array}\end{array}$ \\
\hline
\end{tabular}

Continua...

\footnotetext{
${ }^{1}$ Temática especializada definida segundo a Tabela de Áreas de Conhecimento da Capes: <http://www.capes.gov.br/avaliacao/tabela-de-areas-de-conhecimento>.
} 


\begin{tabular}{|c|c|}
\hline CAMPOS & SUBCAMPOS \\
\hline Serviços que fornece & $\begin{array}{l}\text { empréstimo, atendimento, pesquisa, } \\
\text { disseminação seletiva da informação, } \\
\text { treinamento, eventos culturais, reprografia, } \\
\text { intercâmbio, normalização bibliográfica, outros. }\end{array}$ \\
\hline Produtos que disponibiliza & $\begin{array}{l}\text { alerta bibliográfico, boletins, sumário corrente, } \\
\text { outros. }\end{array}$ \\
\hline Tipo de classificação utilizada & CDD, CDU, LC, outros \\
\hline Redes em que a biblioteca participa & $\begin{array}{l}\text { Aglinet, Antares, Bibliodata, Bibliosus, Bireme, } \\
\text { Bitnet, BLDSC, CCN, Comut, Infoterra, Interdata, } \\
\text { Pergamum, Renap, Renima, Renpac, Repidisca, } \\
\text { RNP, RVBI, Sidra, Sisbacen. }\end{array}$ \\
\hline Automação & sistema de automação utilizado \\
\hline
\end{tabular}

Quadro 1 - Campos e subcampos do formulário eletrônico

\subsection{INTERFACES}

A interface do formulário eletrônico foi desenvolvida com o intuito de tornar o cadastramento o mais amigável possível, facilitando todo o processo que seria realizado de forma independente pelas instituições (ver figura 1).

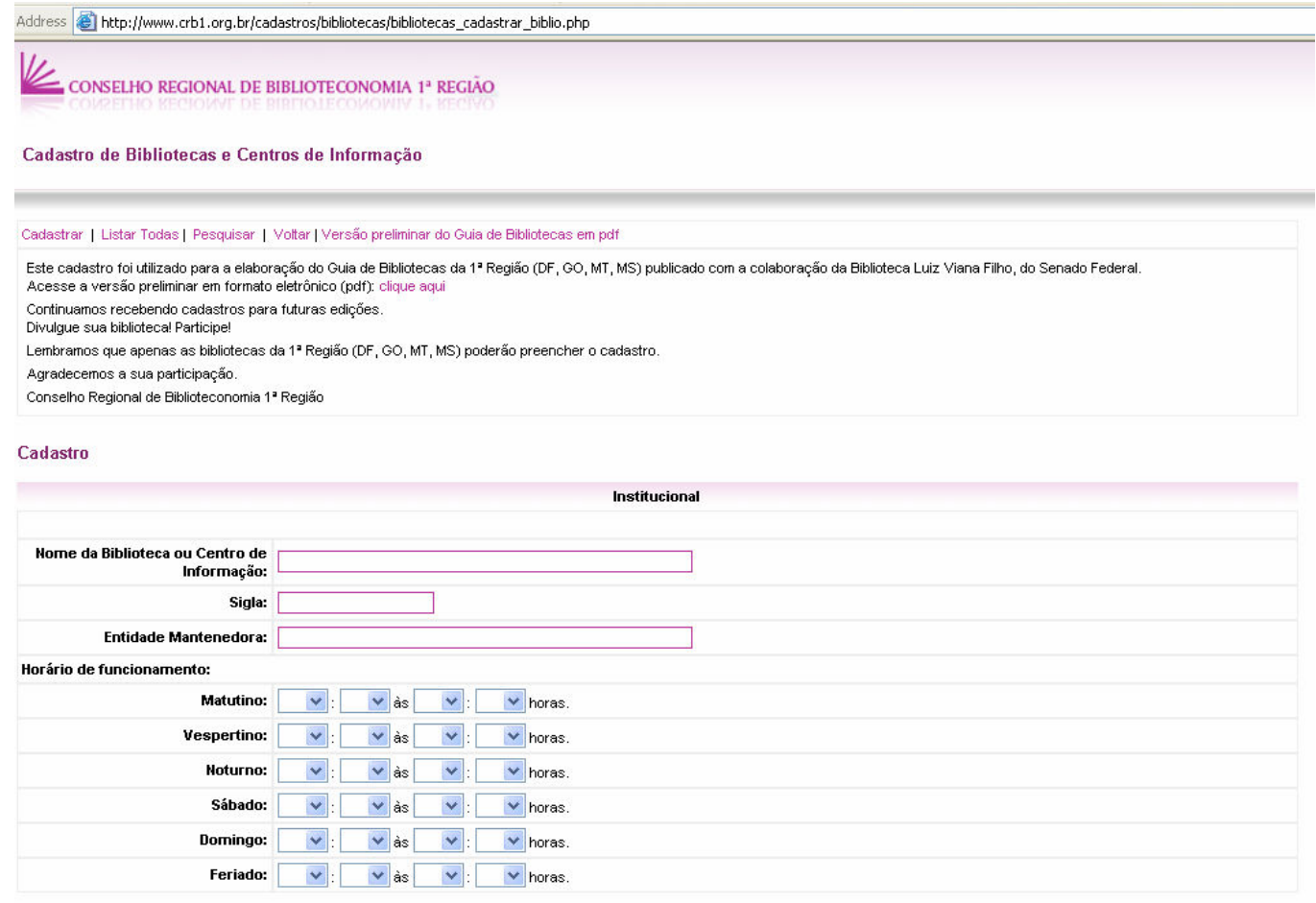

Figura 1 - Interface do cadastro online de bibliotecas da $1^{\text {a }}$ Região 
Com relação às interfaces do formulário utilizado para a pesquisa, duas

versões foram disponibilizadas, a primeira por campos e subcampos e a segunda por menus, conforme figuras 2 e 3 abaixo.

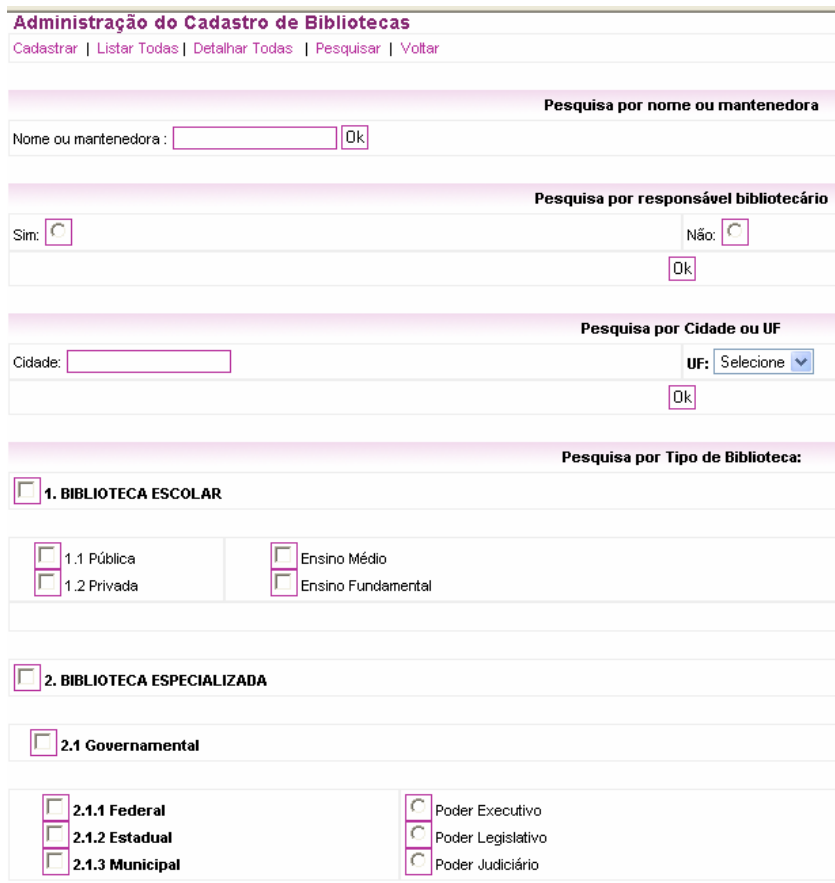

Figura 2 - Interface da página de pesquisa por campos e subcampos

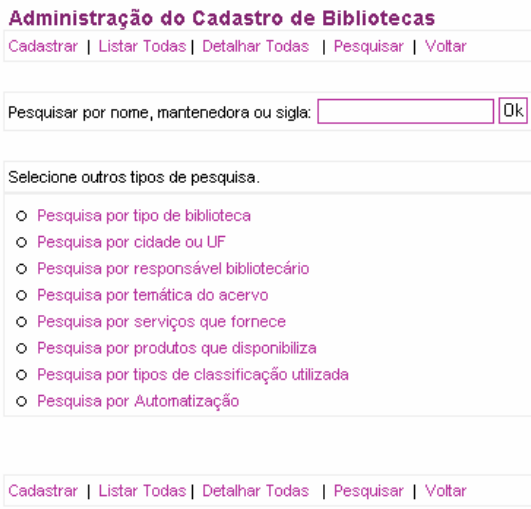

Figura 3 - Interface da página de pesquisa por menus
por uma unidade de informação é
A seguir, ver figura 4, a interface da apresentada.
página contendo o resultado de pesquisa 


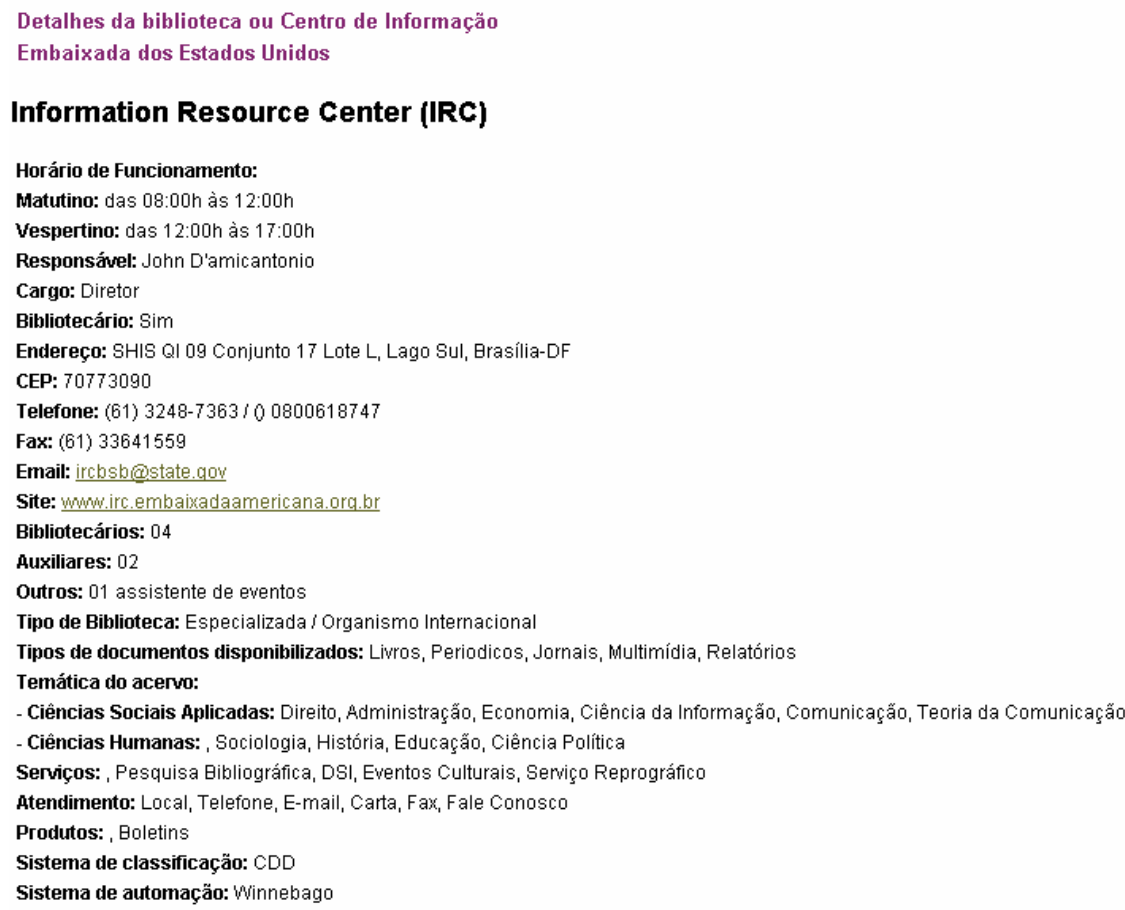

Figura 4 - Interface do resultado da pesquisa

\section{CONSIDERAÇÕES FINAIS}

A gestão 2006/2008 do Conselho Regional de Biblioteconomia $1^{\text {a }}$ Região cumpriu uma de suas principais competências com a atualização e publicação do cadastro de bibliotecas. Percebe-se que esta iniciativa contribuiu para uma melhora da imagem e reputação do CRB-1 perante a comunidade bibliotecária.

Nota-se que as diversas tecnologias disponíveis, aliadas às facilidades proporcionadas pela Internet, agilizam o procedimento utilizado para a publicação de cadastros e guias de instituições, desde a coleta dos dados institucionais até a publicação e divulgação do produto final.
A versão eletrônica do guia de bibliotecas possui algumas vantagens se comparada à versão impressa: (I) sua estrutura e conteúdo podem ser modificados com maior rapidez e menor custo; desse modo, a manutenção, a atualização e a expansão do guia podem ser operacionalizadas com maior facilidade; (II) o acesso aos dados contidos em um guia eletrônico é simples e direto o esquema de navegação por uma ou várias páginas disponibilizadas via Internet, no formato de hipertexto, é bem intuitivo, tornando a tarefa de busca e recuperação de informações mais agradável.

Espera-se que este artigo possa servir de suporte para futuras atuações de Conselhos Regionais de Biblioteconomia, associações de bibliotecários e demais 
instituições e/ou profissionais que se envolvam no desenvolvimento e elaboração de cadastros e guias de bibliotecas e unidades de informação. A criação de sistemas e de metadados desses cadastros on-line deve ser realizada de forma padronizada e segundo as normas vigentes para que o intercâmbio de dados possa ser alcançado de forma eficiente, diminuindo esforços duplicados. Estas recomendações poderiam contribuir para a geração de um Guia de Bibliotecas e unidades de informação brasileiras, possibilitando dar maior visibilidade para estas instituições em nível nacional e internacional.

Apesar do enorme esforço para disponibilizar informações atualizadas e confiáveis, os dados disponíveis no Guia são mutáveis e deverão ser atualizados periodicamente por futuras gestões do CRB-1. Esse pressuposto deve ser considerado por todas as instituições envolvidas com o cadastro de bibliotecas, realizando atualização constante desses documentos e recursos.

É importante lembrar que apesar de toda a evolução tecnológica a necessidade de se conhecer as fontes e saber identificar e promover o acesso à informação pertinente continua sendo tão importante quanto sempre foi para os profissionais que se dedicam ao atendimento ao usuário (CAMPELLO; CENDÓN; KREMER, 2000, p. 33).

\section{REFERÊNCIAS}

ASSOCIAÇÃO BRASILEIRA DE NORMAS TÉCNICAS - ABNT. NBR 10518:

preparação de guias de bibliotecas, centros de informação e documentação. Rio de Janeiro, 1992.

. NBR 6034: preparação de índice de publicações. Rio de Janeiro, 1989.

ASSOCIAÇÃO DOS BIBLIOTECÁRIOS DO DISTRITO FEDERAL - ABDF. Guia das bibliotecas de Brasília. Brasília, 1970. . Diretório de bibliotecas e/ou

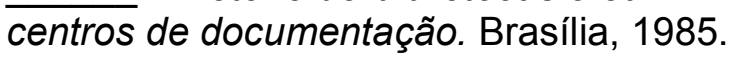

ASSOCIAÇÃO PAULISTA DE BIBLIOTECÁRIOS - APB. Grupo de informação e documentação jurídica. Guia de bibliotecas jurídicas do Estado de São Paulo. 2. ed. São Paulo, 1994.

Grupo de Trabalho de Bibliotecas de Ciências Sociais e Humanas. Guia de Bibliotecas de Ciências Sociais e Humanas do Estado de São Paulo. São Paulo, 1973. . Grupo de Trabalho em Tecnologia. Bibliotecas em tecnologia do Estado de São Paulo: informações gerais. São Paulo: Laboratório de Hidráulica EPUSP/DAEE, 1970.

ASSOCIAÇÃO PROFISSIONAL DE BIBLIOTECÁRIOS DE PERNAMBUCO APBPE. Guia das bibliotecas e bibliotecários do Recife. 2. ed. Recife, 1971.

BIBLIOTECA PÚBLICA DO PARANÁ BPP. Sistema Estadual de Bibliotecas Públicas do Paraná. Guia de Bibliotecas Públicas Municipais do Paraná. Curitiba, 2004. Disponível em:

<http://www.pr.gov.br/bpp/guia_enderecos. rtf>. Acesso em: 10 maio 2008.

BRASIL. Ministério da Educação e Cultura. Coordenação de Aperfeiçoamento de Pessoal de Nível Superior. Guia de 
bibliotecas universitárias brasileiras.

Brasília: CAPES, 1979. 2 v.

CALDEIRA, Paulo da Terra. Guia das bibliotecas do estado de Minas Gerais. Belo Horizonte: Conselho de Extensão da UFMG, 1977.

CAMPELLO, Bernadete S.; CENDÓN, Beatriz V.; KREMER, Jannette M.(Org.) Fontes de informação para pesquisadores e profissionais. Belo Horizonte: Ed. da UFMG, 2000.

CARVALHO, Elizabeth Maria Ramos de; RAPOSO, Maria de Fátima Pereira; FIGUEIREDO, Maria da Graça Botelho. Guia de bibliotecas e serviços de documentação da área tecnológica do Paraná e do Rio Grande do Sul. Rio de Janeiro: FEBAB, 1979.

CARVALHO, Elizabeth Maria Ramos de; SANTOS, Ivana C. M. dos; FIGUEIREDO, Maria da Graca Botelho. Guia das bibliotecas e serviços de documentação da área tecnológica do Rio de Janeiro. Rio de Janeiro: APB/RJ, 1977.

COMISSÃO BRASILEIRA DE BIBLIOTECAS UNIVERSITÁRIAS - CBBU. Guia de bibliotecas de instituições brasileiras de ensino superior. 2. ed. rev. ampl. Rio de Janeiro: Universidade Federal do Rio de Janeiro, 1998. pt. 1:

Norte/Nordeste/Sudeste.

COMISSÃO BRASILEIRA DE INFORMAÇÃO E DOCUMENTAÇÃO JURÍDICA - CBIDJ. Grupo de Informação e Documentação Jurídica do Rio de Janeiro. Guia de bibliotecas jurídicas. 2. ed.rev.ampl. Rio de Janeiro: CIDJ/RJ, 1994.

\section{CONFEDERAÇÃO NACIONAL DA}

INDÚSTRIA - CNI. Guia de Bibliotecas do Sistema Indústria. Brasília, 2005.

Disponível em:

<http://www.sistemacni.org.br/guiadebibliot ecas/>. Acesso em: maio 2008.
CONSELHO NACIONAL DE

DESENVOLVIMENTO CIENTÍFICO E TECNOLÓGICO - CNPq. Habitat: guia de bibliotecas e centros de documentação. Brasília, 1982.

CONSELHO REGIONAL DE BIBLIOTECONOMIA - CRB 1 REGIÃO. Guia das bibliotecas de Brasilia. Brasilia: ABDF, 1975. $52 \mathrm{p}$

Regimento Interno: Conselho Regional de Biblioteconomia - $1^{\mathrm{a}}$ Região. Brasília, 2002. Disponível em: <http://www.crb1.org.br/legislacao/pdf/Regi mentoCRB1.pdf>. Acesso em: 5 mar. 2008.

. Guia de bibliotecas da $1^{a}$ Região: Distrito Federal, Acre, Goiás, Mato Grosso, Mato Grosso do Sul, Território de Rondônia. Brasília, 1981.

. Guia de bibliotecas da $1^{a}$ Região:

Distrito Federal, Goiás, Mato Grosso e Mato Grosso do Sul. Brasília: Senado Federal, Biblioteca Acadêmico Luiz Viana Filho, 2008. Disponível em: <http://www.crb1.org.br/noticias/UserFiles/fi le/Guia-de-bibliotecas.pdf>. Acesso em: 5 mar. 2008.

Federal. Brasília, 1996.

CONSELHO REGIONAL DE

BIBLIOTECONOMIA - CRB $7^{\text {a }}$ REGIÃO.

Guia de bibliotecas, centros de documentação e informação do Estado do Rio de Janeiro. Rio de Janeiro: Rabiskus, 1993.

CONSELHO REGIONAL DE

BIBLIOTECONOMIA - CRB 8. REGIÃO.

Bibliotecas do Estado de São Paulo cadastradas no CRB-8. São Paulo, 1988.

CUNHA, Murilo Bastos da. Para saber mais: fontes de informação em ciência e tecnologia. Brasília: Briquet de Lemos/Livros, 2001. 
FUNDAÇÃO BIBLIOTECA NACIONAL.

Guia das bibliotecas públicas do Brasil: 1994/1995. Rio de Janeiro, 1994.

FUNDAÇÃO INSTITUTO BRASILEIRO DE GEOGRAFIA E ESTATÍSTICA - IBGE. Guia das bibliotecas brasileiras: 1976. 2. ed. Rio de Janeiro: IBGE/INL, 1979.

HIRSCHBERG, Alice Irene et al. Cadastro de unidades de documentação $e$ bibliotecas brasileiras de educação. São Paulo: FDE, 1990. (Série Apoio, 5).

INSTITUTO BRASILEIRO DE BIBLIOGRAFIA E DOCUMENTAÇÃO IBBD. Bibliotecas especializadas brasileiras. 2.ed. Rio de Janeiro, 1969. (Fontes de Informação, 2).

INSTITUTO BRASILEIRO DE INFORMAÇAO EM CIÊNCIA E TECNOLOGIA - IBICT. Quem informa no Brasil: guia de bibliotecas, centros e serviços de documentação e informação. Brasília, 1987.

INSTITUTO ESTADUAL DO LIVRO - IEL. Bibliotecas estaduais e municipais do Rio de Janeiro. Rio de Janeiro, 1979.

INSTITUTO NACIONAL DO LIVRO - IEL. Guia das bibliotecas públicas brasileiras conveniadas com o Instituto Nacional do Livro. [Brasília]: MEC/Fundação Nacional Pro-Memoria/INL, 1983.

. Guia das bibliotecas brasileiras. 4.

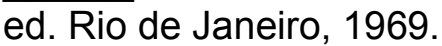

MOGI, Matie. Guia de bibliotecas Universidades Federais. Brasília: IBICT, 1996. 1 v. (Memória técnica do IBICT; MT/1092).

NEGRINE, Airton da Silva. Guia das bibliotecas da grande Porto Alegre: para pesquisa bibliográfica educacional. Porto Alegre: Universidade Federal do Rio Grande do Sul, 1976.

RIO DE JANEIRO (Estado). Secretaria Estadual de Cultura. Guia de Bibliotecas
Públicas do Estado do Rio de Janeiro. Rio de Janeiro: FAPERJ, 2002. Disponível em: $<$ http://www.bperj.rj.gov.br/sebguiadebibliot ecas_novo.htm>. Acesso em: 10 maio 2008.

SANTOS, Lucia Maria Gurjão dos. Guia das bibliotecas de Teresina. Teresina: Fundação CEPRO, 1980. Guia das bibliotecas de Teresina. Teresina: Fundação CEPRO, 1983.

SÃO PAULO (Estado). Secretaria de Estado da Cultura. Guia das Bibliotecas Públicas Municipais do Estado de São Paulo. São Paulo: Secretaria de Estado da Cultura, 1988.

SÃO PAULO (Estado). Departamento de Estatística do Estado. Bibliotecas Públicas e semipúblicas do Estado de São Paulo: cadastro, por município, em 31-XII-1959. [São Paulo]: Universidade de São Paulo, 1960.

Bibliotecas públicas e semipúblicas do Estado de São Paulo: cadastro, por município, em 31/XII/1960. São Paulo: Departamento de Estatística do Estado, 1961.

SERVIÇO NACIONAL DE APRENDIZAGEM INDUSTRIAL - SENAI (Rio de Janeiro). Diretório de bibliotecas e centros de documentação

SENAI/EMPRESAS. Rio de Janeiro, 1986.

TAVARES, Maria Teresa Wiltgen.

Bibliotecas no Rio Grande do Sul: 19711972. Porto Alegre: Secretaria de

Coordenação e Planejamento, 1973.

UNIVERSIDADE DE SÃO PAULO - USP. Guia das bibliotecas da Universidade de São Paulo. São Paulo: USP Coordenadoria de Atividades Culturais; São Paulo: Biblioteca Central, 1973. Guia das bibliotecas da Universidade de São Paulo. 2.ed. São Paulo: USP - Coordenadoria de Atividades 
Culturais; São Paulo: Biblioteca Central, 1978.

. Sistema Integrado de Bibliotecas. Guia das bibliotecas SIBI/USP. São Paulo, 1988.

UNIVERSIDADE FEDERAL DO PIAUI UFP. Biblioteca Central. Guia das bibliotecas universitárias brasileiras. Teresina, 1979.

UNIVERSIDADE FEDERAL DO RIO DE JANEIRO - UFRJ. Sistema de Bibliotecas e Informação. Guia de bibliotecas de instituições brasileiras de ensino superior. Rio de Janeiro: UFRJ/SIBI/CR, 1994. 2 v.

Sistema de Bibliotecas e Informação. Guia de bibliotecas e Postos de Serviços de Informação: SiBI/UFRJ. Rio de Janeiro, 2005. Disponível em: <http://www.sibi.ufrj.br/guia.pdf>. Acesso em: 10 maio 2008.

. Sistema de Bibliotecas e Informação. Guia de bibliotecas e unidades de informação UFRJ/SIBI. Ed. preliminar. Rio de Janeiro, 1988.

. Sistema de Bibliotecas e Informação. Guia de bibliotecas e unidades de informação: SIBI/UFRJ. 2. ed. Rio de Janeiro, 1991.

\section{Title}

Library guides as information sources: methodology used in the $1^{\text {st }}$ region directory organization.

\begin{abstract}
This paper highlights the Library Science Regional Council's role in creating and maintaining libraries' guides, the benefits of these documents in promoting these institutions and also the importance of these guides as information resources. It presents some professionals and institutions initiatives in
\end{abstract}

publishing Libraries' guides in Brazil. Finally, it describes the methodology applied for the libraries registration process, which resulted in the publication of the "First Region Libraries' Guide", both in print and electronic versions.

\section{Keywords}

Information Source. Library Directory. Library Guide.

\section{Título}

Guías de las bibliotecas como fuentes de información: metodología de elaboración de lo guía de la $1^{\text {a }}$ región.

\section{Resumen}

Este trabajo señala la función del Consejo Regional de Biblioteconomía en la elaboración y manutención de los registros de bibliotecas y unidades de información, la importancia de los registros de bibliotecas y unidades de información en la divulgación de estas entidades, y también como fuentes bibliográficas para informaciones que interesan el usuario. Relaciona las iniciativas de profesionales e instituiciones en la publicación de guías de bibliotecas en Brasil. Al final, describe la metodología para el registro de las bibliotecas que resultó en la publicación del "Guia de Bibliotecas da $1^{\text {a }}$ Região" en medio impreso y electrónico.

\section{Palabras Clave}

Fuentes de información. Guía de bibliotecas. Directorio de bibliotecas.

Recebido em: 02.07.2008

Aceito em: 05.02.2009 